\title{
Prevalence of Hepatitis C Virus IgG and Cytomegalovirus IgG in Serum of Type 2 Diabetes Mellitus Patients
}

\author{
Neveen George El-Antouny ${ }^{1}$, Rana Mostafa Yousef ${ }^{* 1}$, Rehab Ahmed Rabie ${ }^{2}$, Heba Shafeak Abdelkhalik ${ }^{1}$ \\ Departments of ${ }^{1}$ Internal Medicine and ${ }^{2}$ Medical Microbiology and Immunology, \\ Faculty of Medicine, Zagazig University, Egypt \\ *Corresponding author: Rana Mostafa Yousef, mobile: (+20)01064380457, Email: rolaali335@gmail.com
}

\begin{abstract}
Background: There are several organized factors which influence the development of diabetes among HCV-infected patients like age, sex, and family history of diabetes. Patients with diabetes mellitus type 2 (T2DM) have higher risk to be infected with hepatic viruses, as hepatitis B or C virus.

Objective: This study aimed to notice the prevalence of $\mathrm{HCV}$ and cytomegalovirus in patients with type 2 diabetes mellitus.

Patients and methods: A case-control study included 95 patients with T2DM and 95 apparently healthy individuals. We evaluated the seroprevalence of two viral antibodies including (CMV IgG, HCV IgG) beside Hepatitis B surface antigen (HBsAg) in patients with T2DM in comparison to the control group.

Results: There was a significant increase in $\mathrm{HCVAb}(\operatorname{IgG})$ positive patients in diabetic group compared to control group. There was a significant association between HCVAb (IgG) with systolic blood pressure ( $\mathrm{mmHg}$ ), diastolic blood pressure $(\mathrm{mmHg})$, mean arterial blood pressure $(\mathrm{mmHg}), \mathrm{WBCs}$, platelets and ALT. There was a significant association between CMV IgG with age, systolic blood pressure, and mean arterial blood pressure. There was a significant association between HBV Ag with ALT, AST.

Conclusion: Seropositive of anti-HCV and CMV IgG were presented in higher rate on T2DM patients than control. This confirmed a strong association between HCV, and cytomegalovirus among T2DM patients.

Keywords: CMV, HBsAg, HCV, T2DM.
\end{abstract}

\section{INTRODUCTION}

Type 2 diabetes is characterized by a combination of peripheral insulin resistance and inadequate insulin secretion by pancreatic beta cells. Insulin resistance has been attributed to elevated levels of free fatty acids and pro-inflammatory cytokines in plasma. It also leads to decreased glucose transport into muscle cells, elevated hepatic glucose production, and increased breakdown of fat ${ }^{(\mathbf{1})}$. The etiology of DM is still enigmatic. Complex interaction of genetic, metabolic, and environmental factors contributes to type $2 \mathrm{DM}$ development ${ }^{(2)}$.

Cytomegalovirus (CMV) is a herpes viral genus of the Herpesviruses group which is prevalent worldwide with an estimated seroprevalence nearly of $45 \%$ in the general population. In humans it is commonly known as Human CMV or Human Herpesvirus 5 (HHV-5) ${ }^{(3)}$.

Human CMV may infect several organs/and is transmitted through infected body secretions; saliva, cervical fluid, semen, urine, breast milk, blood and organ allografts ${ }^{(4)}$. Control of CMV and its complications and reduction of its transmission are in the interest of public health ${ }^{(5)}$. The seroprevalence of selected viruses was studied in a group of predominantly Hispanic patients with type 2 diabetes and controls without diabetes. They indicated an up to 12 times greater odds of having type 2 diabetes for persons previously exposed to CMV. Since accelerated atherosclerosis is also associated with diabetes and $\mathrm{CMV}$, past CMV infection may be a common factor that links atherosclerosis and diabetes ${ }^{\left({ }^{(}\right)}$.
Egypt has the highest HCV prevalence in the world and the highest prevalence of HCV (67\%), which reflects a national-level epidemic. HCV infection and its complications are among the leading public-health challenges in Egypt ${ }^{(7)}$. Several studies reported that $\mathrm{HCV}$ infection may also contribute to the development of diabetes, and higher prevalence of type 2 diabetes mellitus has been observed in the developed world ( $2 \%$ to $9.4 \%$ ) in patients with $\mathrm{HCV}$ infection than in those with other forms of chronic hepatitis ${ }^{(8)}$.

The aim of the current study was to notice the prevalence of $\mathrm{HCV}$ and cytomegalovirus in patients with type 2 diabetes mellitus.

\section{PATIENTS AND METHODS}

A case-control study included 95 patients with T2DM and 95 apparently healthy individuals. This study was done at Internal Medicine Department and Microbiology Department, Zagazig University Hospitals.

\section{Ethical considerations:}

The study was approved by the Zagazig University Institution Review Board (IRB). Official permission from study setting department was taken and an informed written consent was obtained from all patients before they joined the study. This work has been carried out in accordance with The Code of Ethics of the World Medical Association (Declaration of Helsinki) for studies involving humans. 
Inclusion criteria: Patients with type T2DM of both genders.

Exclusion criteria: Patients with type 1 diabetes mellitus, patients with end-organ failure (hepatic/renal or cardiac), patients with maturity onset diabetes of the young (MODY), patients with evidence of malignancy and patient refusal.

\section{Specific investigations:}

1-HCV Ab (IgG) and CMV (IgG) using a commercial electrochemiluminescence assay (ECLIA): Immunoassay for the in vitro qualitative detection of antibodies to HCV in human adult serum. The result of a sample was given in the form of a cutoff-index (signal sample/cutoff) with a result interpretation of: "non-reactive" $(\mathrm{COIc})<0.90)$ " "border"d $)(0.90 \leq \mathrm{COI}$ $<1.00)$ or "reactive" $(\mathrm{COI} \geq 1.00) \mathrm{c}) \mathrm{COI}=$ cutoff indexd) border $=$ borderline.

2-CMV IgG using a commercial electrochemiluminescence assay (ECLIA): For the quantitative determination of $\operatorname{IgG}$ Antibodies to Cytomegalovirus (CMV) in serum. Results were determined via a calibration curve, which is instrument specifically generated by 2 point calibration and a master curve provided via the reagent barcode.

\section{Statistical analysis}

Data were analyzed using the statistical package for the social sciences, version 20.0 (SPSS Inc., Chicago, Illinois, USA). Quantitative data were expressed as mean \pm standard deviation (SD). Qualitative data were expressed as frequency and percentage. Independent-samples t-test and Chi-square $\left(\mathrm{X}^{2}\right)$ test were used to compare quantitative and qualitative data respectively. P-value $<0.05$ was considered significant and P-value $<0.001$ was considered highly significant.

\section{RESULTS}

The results of the current study showed statistically significant decrease in hemoglobin $(\mathrm{Hb})$, platelets, albumin and HDL in diabetes group compared to control group, while significant increase in WBCs, RBS, HbA1C, ALT, AST, creatinine, urea, cholesterol, LDL and TG in diabetes group compared to control group (Table 1).

Table (1): Comparison between diabetes group and control group according to laboratory data

\begin{tabular}{|c|c|c|c|c|}
\hline Laboratory data & $\begin{array}{c}\text { Diabetes Group } \\
(\mathbf{n}=95) \\
\text { Mean } \pm \text { SD }\end{array}$ & $\begin{array}{c}\text { Control Group } \\
(\mathbf{n}=95) \\
\text { Mean } \pm \text { SD }\end{array}$ & $\begin{array}{c}\text { Total } \\
(\mathbf{n}=\mathbf{1 9 0}) \\
\text { Mean } \pm \text { SD }\end{array}$ & p-value \\
\hline WBCs (thousand/mcL) & $9.21 \pm 2.58$ & $7.22 \pm 1.95$ & $7.21 \pm 1.28$ & $<0.001 * *$ \\
\hline RBCs (millions/mcL) & $4.02 \pm 0.71$ & $4.14 \pm 0.53$ & $4.08 \pm 0.63$ & 0.212 \\
\hline $\mathrm{Hb}(\mathrm{g} / \mathrm{dL})$ & $11.32 \pm 1.68$ & $12.07 \pm 1.24$ & $11.70 \pm 1.52$ & $<0.001 * *$ \\
\hline Platelets (thousand/mcL) & $237.25 \pm 9.39$ & $269.36 \pm 9.83$ & $253.31 \pm 9.33$ & $0.015^{*}$ \\
\hline RBS (mg/dL) & 243.209 .60 & $158.36 \pm 5.87$ & $200.78 \pm 9.48$ & $<0.001 * *$ \\
\hline HbA1C (\%) & $8.19 \pm 1.78$ & $5.29 \pm 0.40$ & $6.74 \pm 1.94$ & $<0.001 * *$ \\
\hline ALT (U/I) & $40.12 \pm 17.25$ & $28.25 \pm 5.49$ & 29.183 .30 & $<0.001 * *$ \\
\hline AST (U/l) & $33.73 \pm 2.16$ & $28.74 \pm 5.24$ & $31.24 \pm 15.31$ & $0.024^{*}$ \\
\hline Bilirubin $(\mu \mathrm{mol} / \mathrm{L})$ & $0.89 \pm 0.19$ & $0.85 \pm 0.23$ & $0.87 \pm 02$ & 0.382 \\
\hline $\operatorname{Albumin}(\mathrm{g} / \mathrm{L})$ & $3.66 \pm 0.65$ & $3.97 \pm 0.58$ & $3.81 \pm 0.63$ & $<0.001 * *$ \\
\hline Creatinine (mg) & $1.06 \pm 0.26$ & $0.89 \pm 0.22$ & $0.97 \pm 0.20$ & $0.047 *$ \\
\hline Urea (mg/dL) & $45.48 \pm 5.62$ & $31.57 \pm 5.66$ & $38.53 \pm 2.30$ & $<0.001 * *$ \\
\hline Cholesterol (mg/dL) & $212.99 \pm 50.85$ & $186.33 \pm 5.77$ & $199.66 \pm 5.41$ & $<0.001 * *$ \\
\hline LDL (mg/dL) & $137.91 \pm 34.74$ & $108.96 \pm 8.72$ & $113.43 \pm 32.10$ & $<0.001 * *$ \\
\hline HDL (mg/dL) & $43.03 \pm 5.65$ & $49.40 \pm 7.88$ & $46.22 \pm 7.55$ & $<0.001 * *$ \\
\hline Triglyceride (mg/dL) & $159.07 \pm 9.14$ & $124.97 \pm 4.50$ & $132.02 \pm 5.25$ & $<0.001 * *$ \\
\hline
\end{tabular}

*: Significant difference, $* *$ : Highly significant difference

There was a significant increase in $\mathrm{HCVAb}(\mathrm{IgG})$ positive patients in diabetic group compared to control group (Table 2).

Table (2): Comparison between diabetes group and control group according to HCVAb (IgG)

\begin{tabular}{|l|c|c|c|c|}
\hline HCVAb (IgG). & $\begin{array}{c}\text { Diabetes Group } \\
(\mathbf{n = 9 5})\end{array}$ & $\begin{array}{c}\text { Control Group } \\
(\mathbf{n}=\mathbf{9 5})\end{array}$ & $\begin{array}{c}\text { Total } \\
(\mathbf{n = 1 9 0})\end{array}$ & \multirow{2}{*}{ p-value } \\
\hline Positive & $36(37.9 \%)$ & $18(18.9 \%)$ & $54(28.4 \%)$ & \multirow{2}{*}{$0.004 *$} \\
\hline Negative & $59(62.1 \%)$ & $77(81.1 \%)$ & $136(71.6 \%)$ & \\
\hline
\end{tabular}

*: Significant difference

There was a significant association between HCVAb (IgG) with systolic blood pressure ( $\mathrm{mmHg})$, diastolic blood pressure $(\mathrm{mmHg})$, mean arterial blood pressure (mmHg), WBCs, Platelets and ALT (Table 3). 
Table (3): Association between HCVAb (IgG) with all parameters in diabetic group (n=95)

\begin{tabular}{|c|c|c|c|c|c|}
\hline \multirow[t]{2}{*}{ Parameters } & \multicolumn{2}{|c|}{$\begin{array}{c}\text { Positive HCV IgG } \\
(n=36)\end{array}$} & \multicolumn{2}{|c|}{$\begin{array}{c}\text { Negative HCV } \\
\text { IgG }(n=59)\end{array}$} & \multirow[t]{2}{*}{ p-value } \\
\hline & Mean & \pm SD & Mean & \pm SD & \\
\hline Age (years) & 57.22 & 9.24 & 53.92 & 9.07 & 0.090 \\
\hline $\operatorname{Sex}[M / F]$ & $18 / 18$ & $50 / 50 \%$ & $23 / 36$ & $39 / 61 \%$ & 0.293 \\
\hline BMI $[w t /(h t) \wedge 2]$ & 31.40 & 3.93 & 31.06 & 3.35 & 0.654 \\
\hline Systolic blood pressure (mmHg) & 145.00 & 21.04 & 123.31 & 20.98 & $<0.001 * *$ \\
\hline Diastolic blood pressure (mmHg) & 81.25 & 14.71 & 76.61 & 11.00 & 0.083 \\
\hline Mean Arterial Blood pressure (mmHg) & 105.78 & 16.41 & 92.19 & 13.36 & $<0.001 * *$ \\
\hline WBCs (thousand/mcL) & 9.18 & 2.95 & 9.22 & 2.35 & 0.942 \\
\hline RBCs (millions/mcL) & 4.03 & 0.76 & 4.02 & 0.69 & 0.922 \\
\hline $\mathrm{Hb}(\mathrm{g} / \mathrm{dL})$ & 11.45 & 2.05 & 11.25 & 1.42 & 0.579 \\
\hline Platelets (thousand/mcL) & 215.03 & 82.14 & 248.61 & 67.91 & $0.034 *$ \\
\hline RBS (mg/dL) & 263.25 & 102.72 & 230.97 & 96.48 & 0.126 \\
\hline $\operatorname{Hg} \operatorname{A1C}(\%)$ & 8.46 & 2.10 & 8.03 & 1.56 & 0.254 \\
\hline ALT (U/I) & 35.78 & 2.63 & 42.77 & 9.17 & $0.046^{*}$ \\
\hline AST (U/I) & 32.04 & 2.71 & 34.76 & 3.63 & 0.527 \\
\hline Bilirubin $(\mu \mathrm{mol} / \mathrm{L})$ & 0.94 & 0.09 & 0.86 & 0.01 & 0.363 \\
\hline $\operatorname{Albumin}(\mathrm{g} / \mathrm{L})$ & 3.73 & 0.69 & 3.62 & 0.63 & 0.441 \\
\hline Creatinine (mg) & 1.01 & 0.16 & 1.09 & 0.12 & 0.546 \\
\hline Urea $(\mathrm{mg} / \mathrm{dL})$ & 44.76 & 9.18 & 45.93 & 3.45 & 0.830 \\
\hline Cholesterol (mg/dL) & 217.17 & 6.83 & 210.44 & 42.33 & 0.535 \\
\hline LDL $(\mathrm{mg} / \mathrm{dL})$ & 139.07 & 7.77 & 137.20 & 4.03 & 0.801 \\
\hline HDL (mg/dL) & 43.49 & 7.28 & 42.75 & 4.42 & 0.543 \\
\hline Triglyceride (mg/dL) & 165.56 & 9.90 & 155.12 & 4.11 & 0.407 \\
\hline
\end{tabular}

*: Significant difference, $* *$ : Highly significant difference

There was a significant association between CMV IgG with age, systolic blood pressure, and mean arterial blood pressure (Table 4).

Table (4): Association between CMV IgG with all parameters in diabetic group ( $n=95$ )

\begin{tabular}{|c|c|c|c|c|c|}
\hline \multirow{2}{*}{ Parameters } & \multicolumn{2}{|c|}{ Positive CMV IgG (n=65) } & \multicolumn{2}{|c|}{ Negative CMV IgG $(n=30)$} & \multirow{2}{*}{ p-value } \\
\hline & Mean & \pm SD & Mean & \pm SD & \\
\hline Age (years) & 56.71 & 8.96 & 51.83 & 9.04 & $0.016^{*}$ \\
\hline Sex [M/F] (number and \%) & $32 / 33$ & $49 / 51 \%$ & $9 / 21$ & $30 / 70 \%$ & 0.079 \\
\hline BMI $\left[w t /(h t)^{\wedge} 2\right]$ & 31.04 & 3.64 & 31.50 & 3.44 & 0.567 \\
\hline Systolic blood pressure (mmHg) & 146.38 & 20.61 & 138.67 & 20.92 & 0.095 \\
\hline Diastolic blood pressure (mmHg) & 79.69 & 13.34 & 75.50 & 10.70 & 0.134 \\
\hline Mean Arterial Blood pressure (mmHg) & 105.25 & 14.92 & 99.87 & 13.40 & 0.095 \\
\hline WBCs (thousand/mcL) & 9.06 & 2.71 & 9.53 & 2.28 & 0.416 \\
\hline RBCs (millions/mcL) & 4.07 & 0.80 & 3.92 & 0.47 & 0.326 \\
\hline Hb. $(g / d L)$ & 11.35 & 1.84 & 11.27 & 1.28 & 0.844 \\
\hline Platelets (thousand/mcL) & 240.34 & 12.61 & 230.57 & 9.36 & 0.658 \\
\hline RBS (mg/dL) & 243.74 & 9.16 & 242.03 & 14.36 & 0.939 \\
\hline $\operatorname{Hg} \operatorname{A1C}(\%)$ & 8.16 & 1.76 & 8.26 & 1.86 & 0.804 \\
\hline ALT (U/l) & 40.08 & 9.32 & 40.20 & 1.87 & 0.976 \\
\hline AST (U/I) & 33.41 & 2.85 & 34.42 & 2.81 & 0.822 \\
\hline Bilirubin $(\mu \mathrm{mol} / \mathrm{L})$ & 0.94 & 0.12 & 0.78 & 0.17 & $0.047 *$ \\
\hline Albumin $(g / L)$ & 3.60 & 0.67 & 3.80 & 0.60 & 0.161 \\
\hline Creatinine (mg) & 1.04 & 0.28 & 1.09 & 0.22 & 0.725 \\
\hline Urea $(\mathrm{mg} / \mathrm{dL})$ & 44.34 & 2.07 & 47.97 & 3.30 & 0.524 \\
\hline Cholesterol (mg/dL) & 210.97 & 5.49 & 217.37 & 7.67 & 0.571 \\
\hline LDL (mg/dL) & 136.66 & 5.62 & 140.60 & 3.15 & 0.610 \\
\hline HDL (mg/dL) & 42.99 & 5.24 & 43.13 & 6.54 & 0.912 \\
\hline Triglyceride (mg/dL) & 157.62 & 6.25 & 162.23 & 6.87 & 0.726 \\
\hline
\end{tabular}

*: Significant difference

There was a significant association between HBV Ag with ALT, AST (Table 5). 
Table (5): Association between HBsAg with all parameters in diabetic group (n=95)

\begin{tabular}{|c|c|c|c|c|c|}
\hline \multirow[t]{2}{*}{ Parameters } & \multicolumn{2}{|c|}{$\begin{array}{c}\text { Positive HBsAg Ag. } \\
\qquad(n=10)\end{array}$} & \multicolumn{2}{|c|}{$\begin{array}{c}\text { Negative HBsAg Ag. } \\
\qquad(\mathbf{n}=85)\end{array}$} & \multirow[t]{2}{*}{ p-value } \\
\hline & Mean & $\pm \mathrm{SD}$ & Mean & \pm SD & \\
\hline Age (years) & 57.00 & 8.67 & 54.95 & 9.31 & 0.510 \\
\hline Sex $[M / F]$ (number and \%) & $4 / 6$ & $40 / 60 \%$ & $37 / 48$ & $44 / 56 \%$ & 0.831 \\
\hline BMI $\left[w t /(h t)^{\wedge} 2\right]$ & 32.94 & 3.49 & 30.98 & 3.53 & 0.099 \\
\hline Systolic blood pressure (mmHg) & 138.00 & 14.94 & 144.65 & 21.46 & 0.344 \\
\hline Diastolic blood pressure (mmHg) & 72.50 & 11.84 & 79.06 & 12.64 & 0.122 \\
\hline Mean Arterial Blood pressure (mmHg) & 97.80 & 11.17 & 104.22 & 14.87 & 0.190 \\
\hline WBCs (thousand/mcL) & 8.87 & 2.51 & 9.25 & 2.60 & 0.664 \\
\hline RBCs (millions/mcL) & 4.19 & 0.84 & 4.00 & 0.70 & 0.423 \\
\hline $\mathrm{Hb}(\mathrm{g} / \mathrm{dL})$ & 11.62 & 1.64 & 11.29 & 1.69 & 0.559 \\
\hline Platelets (thousand/mcL) & 250.70 & 13.70 & 235.67 & 9.92 & 0.653 \\
\hline RBS (mg/dL) & 240.00 & 9.52 & 243.58 & 10.91 & 0.915 \\
\hline $\operatorname{Hg} \operatorname{A1C}(\%)$ & 7.71 & 0.88 & 8.25 & 1.86 & 0.368 \\
\hline ALT (U/l) & 50.80 & 9.48 & 38.86 & 2.29 & $0.038^{*}$ \\
\hline AST (U/I) & 47.54 & 5.20 & 32.11 & 11.72 & $0.021 *$ \\
\hline Bilirubin $(\mu \mathrm{mol} / \mathrm{L})$ & 0.93 & 0.24 & 0.88 & 0.20 & 0.752 \\
\hline $\operatorname{Albumin}(\mathrm{g} / \mathrm{L})$ & 3.58 & 0.62 & 3.67 & 0.66 & 0.664 \\
\hline Creatinine (mg) & 1.10 & 0.24 & 1.05 & 0.27 & 0.808 \\
\hline Urea $(\mathrm{mg} / \mathrm{dL})$ & 44.50 & 2.81 & 45.60 & 6.78 & 0.899 \\
\hline Cholesterol (mg/dL) & 198.70 & 5.70 & 214.67 & 50.34 & 0.350 \\
\hline LDL (mg/dL) & 137.78 & 5.90 & 137.92 & 4.82 & 0.990 \\
\hline HDL (mg/dL) & 45.15 & 3.13 & 42.78 & 5.84 & 0.212 \\
\hline Triglyceride (mg/dL) & 145.50 & 4.94 & 160.67 & 6.60 & 0.446 \\
\hline
\end{tabular}

*: Significant difference

\section{DISCUSSION}

Rapid incidence and fast growing of diabetes mellitus (DM) around the world, makes it as a major public health concern. According to the International Diabetes Federation (IDF), there are over than 425 million adults globally having diabetes nowadays, and by 2045 the expected cases will be 629 million of people (9). Hepatitis $\mathrm{C}$ virus $(\mathrm{HCV})$ is another significant health problem, which affects over than 180 million of people worldwide, and is considered as a major cause of high morbidity and deaths, that is because its further complication may lead finally to liver cirrhosis and HCC ${ }^{(\mathbf{1 0}, 11)}$. Human Cytomegalovirus (CMV) is one of the most common herpes viruses worldwide, which can cause an asymptomatic lifelong infection with multiple severe complications ${ }^{(\mathbf{1 2})}$.

Clinical reports suggest the contribution of viral $\mathrm{HCV}$ in CMV infection, also CMV infection has a strong effect in post-transplant DM (PTDM), HBV and $\mathrm{HCV}$ infection prevalence in DM2 patients. They concluded that low prevalence of $\mathrm{HBV}$ and high prevalence $\mathrm{HCV}$ was found in DM2 patients and whether the co-infections with $\mathrm{CMV}$ and $\mathrm{HCV}$ potentiate the risk of DM is still unclear ${ }^{(13)}$.

This study included 95 patients with T2DM and 95 healthy individuals as a control. All subjects were selected from Internal Medicine Department, Zagazig University Hospitals. The present study was designated to evaluate the seroprevalence of two viral antibodies, (CMV IgG and HCV IgG)/ beside Hepatitis B surface antigen ( $\mathrm{HBsAg})$ in diabetic patients compared to the control group.

In our study as regard laboratory parameters, there was significant decrease in $\mathrm{Hb}$, platelets, albumin and HDL in diabetes group compared to control group, while significant increase in WBCS, RBS, HbA1C, ALT, AST, creatinine, urea, cholesterol, LDL and triglyceride in diabetes group compared to control group. The study results showed statistically significant increase in $\mathrm{HCVAb}(\mathrm{IgG})$ positive patients in diabetic group (37.9\%) compared to control group (18.9\%). This agrees with Fabiani $\boldsymbol{e t}$ al. ${ }^{(14)}$ as they found that, the prevalence of HCV infection in T2DM patients was higher than in non-diabetic patients.

According to association between HCVAb (IgG) with all parameters in diabetic group, we found significant association between HCVAb (IgG) with systolic blood pressure $(\mathrm{mmHg})$, diastolic blood pressure $(\mathrm{mmHg})$, mean arterial blood pressure (mmHg), WBCs, platelets and ALT. The mechanisms of $\mathrm{HCV}$ infection for acceleration type $2 \mathrm{DM}$ are through direct viral effects, proinflammatory, other immune-mediated factors, cytokines, chemokines, and other insulin resistance factors mechanisms. This was reinforced by an experimental trial, which showed that expression core protein of the HCV could stimulate hepatic insulin resistance by modifications of the insulin receptor substrate 1 signaling pathway ${ }^{(15)}$.

In comparison between diabetic and control group according to CMV infection, we found significant 
increase in cytomegalovirus $\operatorname{IgG}$ positive patients in diabetic group (68.4\%) compared to control group (49.5). These results are consistent with Chen et al. ${ }^{(16)}$ who found that a role for CMV infection in the pathogenesis of type 2 diabetes in the elderly. Similarly, Yoo et al. ${ }^{(17)}$ found the group with T2DM had higher incidence of CMV diseases than the group without T2DM.

While studying the association between CMV IgG in all diabetic patients, the statistical analysis showed significant association between CMV IgG with age, systolic blood pressure, mean arterial blood pressure and bilirubin, and no significant association with glycemic control represented by $\mathrm{HbA}_{1} \mathrm{C}$. A study by Lohr and Oldstone ${ }^{(18)}$ defined nucleic acid sequences specific for CMV in (44\%) samples of pancreatic tissues from patients with type 2 diabetes mellitus. There were no nucleic acid sequences for 49 non-diabetic controls. These conclusions suggested a possible association of human CMV with type 2 diabetes.

While studying the association between HBV with all parameters in diabetic patients only, we found statistically significant association between $\mathrm{HBsAg}$ with ALT and AST. HBV infection elevates liver enzymes. These results were in agreement with Chen $\boldsymbol{e t}$ al. ${ }^{(19)}$, who identified that the seropositive incidence rates of HBsAg is (13.54\%) in type $2 \mathrm{DM}$ patients and $(12.4 \%)$ in control individuals, with no significant association between the two groups regarding HBVs Ag.

\section{CONCLUSION}

Seropositive of anti-HCV and CMV IgG were presented in higher rate on T2DM patients than control. This confirmed a strong association between HCV, and cytomegalovirus among T2DM patients.

\section{Financial support and sponsorship: Nil.}

\section{Conflict of Interest: Nil.}

\section{REFERENCES}

1. Nishida T (2017): Diagnosis and clinical implications of diabetes in liver cirrhosis: A focus on the oral glucose tolerance test. Journal of the Endocrine Society, 1(7): 886896.

2. American Diabetes Association (2018): Standards of medical care in diabetes. The Journal of Clinical and Applied Research and Education, 41(1): 1-2.

3. Saber A, Mohammed A (2019): The roles of human cytomegalovirus and Epstein-Barr virus in type 1 diabetes mellitus. Annals of Tropical Medicine and Public Health, 22(09): 90-99.

4. Revello M, Gerna G (2013): State of the Art and Trends in Cytomegalovirus Diagnostics. Chapter II. 18, in: Cytomegaloviruses: From Molecular Pathogenesis to Intervention, Matthias Johannes Reddehase, Niels
Lemmermann (eds.): Caister Academic Press, Norfolk UK, Pp. 380-399.

5. Rawlinson W, Boppana S, Fowler K et al. (2017): Congenital cytomegalovirus infection in pregnancy and the neonate: consensus recommendations for prevention, diagnosis, and therapy. Lancet Infect Dis., 17(6): 177-188.

6. Roberts B, Cech I (2005): Association of type 2 diabetes mellitus and seroprevalence for cytomegalovirus. South Med J., 98(7): 686-692.

7. Barakat E, El Wakeel L, Hagag R (2013): Effects of Nigella sativa on outcome of hepatitis C in Egypt. J World Gastroenterol., 19(16): 2529-2536.

8. Naing C, Mak J, Ahmed S et al. (2012): Relationship between hepatitis $\mathrm{C}$ virus infection and type 2 diabetes mellitus: Meta-analysis. World Journal of Gastroenterology, 18: 1642-1651.

9. Cho N, Shaw J, Karuranga S et al. (2018): IDF Diabetes Atlas: Global estimates of diabetes prevalence for 2017 and projections for 2045. Diabetes Res Clin Pract., 138:271281.

10. Drazilova S, Gazda J, Janicko M et al. (2018): Chronic hepatitis $\mathrm{C}$ association with diabetes mellitus and cardiovascular risk in the era of DAA therapy. Canadian Journal of Gastroenterology and Hepatology, 2018: 6150861 .

11. Ahmad-Abakur E, Abdelkareem M, Abrahim-Holi $M$ et al. (2014): Associations of cytomegalovirus with type I diabetes mellitus among children in Khartoum State. African Journal of Microbiology Research, 8(16): 17301734.

12. Zhang J, Liu Y, Sun $\mathbf{H}$ et al. (2015): High human cytomegalovirus IgG level is associated with increased incidence of diabetic atherosclerosis in type 2 diabetes mellitus PatientsMed Sci Monit., 21:4102-4110.

13. Villar L, Geloneze B, Vasques A et al. (2019): Prevalence of hepatitis B and hepatitis $\mathrm{C}$ among diabetes mellitus type 2 individuals. PLoS One, 14(2): 211193-211198.

14. Fabiani S, Fallahi P, Ferrari S et al. (2018): Hepatitis C virus infection and development of type 2 diabetes mellitus: Systematic review and meta-analysis of the literature. Reviews in Endocrine and Metabolic Disorders, 19(4): 405-420.

15. Ambachew S, Eshetie S, Geremew D et al. (2018): Prevalence of type 2 diabetes mellitus among hepatitis c virus- infected patients: a systematic review and metaanalysis. Dubai Diabetes and Endocrinology Journal, 24(14): 29-37.

16. Chen S, de Craen A, Raz Y et al. (2012): Cytomegalovirus seropositivity is associated with glucose regulation in the oldest old. Results from the Leiden 85plus Study. Immunity \& Ageing, 9(1): 18-23.

17. Yoo S, Han K, Lee $\mathrm{K}$ et al. (2019): Impact of cytomegalovirus disease on new-onset type 2 diabetes mellitus: population-based matched case-control cohort study. Diabetes \& Metabolism Journal, 43: 815-29.

18. Lohr J, Oldstone M (1990): Detection of cytomegalovirus nucleic acid sequences in pancreas in type 2 diabetes. Lancet, 336(8716): 644-648.

19. Chen J, Yang I, Su N et al. (2006): Reveal-HBV Study Group. Risk of hepatocellular carcinoma across a biological gradient of serum hepatitis $B$ virus DNA level. JAMA., 295(1): 65-73. 